\title{
Targeting 12-lipoxygenase as a novel strategy to combat the effects of inflammation on beta cells in diabetes
}

\author{
Jan A. Ehses • Marc Y. Donath
}

Received: 25 November 2014 / Accepted: 4 December 2014 /Published online: 24 December 2014

(C) Springer-Verlag Berlin Heidelberg 2014

\begin{abstract}
Inflammation is a pathological feature of the pancreatic islet in type 1 and 2 diabetes, contributing to islet endocrine cell failure and the onset of hyperglycaemia in both diseases. Indeed, numerous immune targets have recently been found to be altered in type 2 diabetes, but few have yet to be translated to the clinic. Taylor-Fishwick and colleagues aimed to change this by performing proof-of-concept studies investigating the efficacy of small molecule inhibitors of 12lipoxygenase in rodent and human beta cells exposed to proinflammatory cytokines. The results of these studies, published in this issue of Diabetologia (DOI: 10.1007/s00125014-3452-0), build on a wealth of preclinical data that have implicated 12-lipoxygenase in rodent models of type 1 and 2 diabetes. While there remain some unanswered mechanistic questions regarding how cytokines regulate 12-lipoxygenase activation and the downstream consequences of activation, it is hoped that future studies with newly identified selective inhibitors may overcome the in vitro limitations of this study and allow for the eventual clinical translation of these highly interesting findings.
\end{abstract}

Keywords 12-Lipoxygenase - Apoptosis · Cytokines · Diabetes · Hydroxyeicosatetraenoic acid · Inflammation · Insulin secretion · Pancreatic beta cell · Pancreatic islet

\footnotetext{
J. A. Ehses $(\square)$

Faculty of Medicine, Department of Surgery and Department of Cellular \& Physiological Sciences, The University of British Columbia, Child \& Family Research Institute, Room A4-183, 950W 28th Avenue, Vancouver, BC, Canada V5Z 4H4

e-mail: ehses@mail.ubc.ca

URL: http://www.ehseslab.com

URL: http://www.cfri.ca/diabetes

M. Y. Donath

Division of Endocrinology, Diabetes \& Metabolism, University

Hospital Basel, Basel, Switzerland
}

\author{
Abbreviations \\ GPX1 Glutathione peroxidase 1 \\ 12-HETE 12-Hydroxyeicosatetraenoic acid \\ $\mathrm{PLA}_{2} \quad$ Phospholipase A2
}

In addition to the increasing worldwide incidence of diabetes, the classical definitions of type 1 and 2 diabetes are beginning to blur. Classical type 1 diabetes is due to autoimmune attack of the insulin-producing pancreatic beta cell, while type 2 diabetes occurs when pancreatic beta cells fail in the face of insulin resistance [1]. The former is typically juvenile onset, and the latter is most frequently associated with obesity. However, type 1 diabetes is being increasingly diagnosed among adults, and obesity is increasing the incidence of type 2 diabetes among adolescents [2]. Both types of diabetes are clinically diagnosed by the onset of hyperglycaemia, with treatment typically beginning with insulin therapy for type 1 diabetes, while type 2 diabetes is initially treated with improved nutrition, exercise and metformin. Understanding that beta cells are already defective at the onset of type 2 diabetes has also promoted insulin treatment at earlier stages of the disease [3].

It has long been appreciated that inflammation is central to the pathology of the pancreatic islet in type 1 diabetes $[4,5]$. However, recent evidence indicates that inflammation is also a contributor to pancreatic beta and alpha cell failure in type 2 diabetes, with IL-1 and glycoprotein 130 (gp130) receptor cytokines playing prominent roles in these two endocrine cell types, respectively [6-8]. We now know that islet inflammation may be triggered by a combination of inflammasome activation, Toll-like receptor 2 and 4 ligands including NEFA, bacterial wall products $[9,10]$, and islet amyloid polypeptide deposits [11], as well as endocannabinoid [12], and that human islet pathology is characterised by increased numbers of macrophages, $\mathrm{CD} 20^{+} \mathrm{B}$ cells and, potentially, $\mathrm{T}$ cells [6]. 
In addition to islet-localised inflammation in type 2 diabetes, inflammation also impacts insulin target tissues in this disease, including the liver and adipose tissue, increasing insulin resistance and putting further stress on pancreatic endocrine cells [13]. Secondary vascular complications associated with type 2 diabetes (e.g. micro- and macrovascular complications) are also driven by an inflammatory process [14]. In fact, endogenous pathogen-associated molecular patterns and danger-associated molecular patterns appear to be systemically elevated in type 2 diabetes, driving a heightened proinflammatory state in circulating monocytes and monocyte-derived macrophages from individuals with this disease [15]. Thus, a strong case can be made that targeting inflammation may not only reduce glycaemia in diabetes, but also improve numerous disease-associated sequelae.

This presents a therapeutic opportunity for developing antiinflammatory drugs specific to the pathology of type 2 diabetes. While some therapeutics currently on the market to treat type 2 diabetes have secondary anti-inflammatory effects [6], none is specifically directed at immune molecules. This has prompted recent clinical trials investigating novel antiinflammatory drugs in type 2 diabetes with anti-IL-1 $\beta$, salsalate and anti-TNF $\alpha$ being the most advanced [16]. However, these immune targets are not the only pathways altered in individuals with type 2 diabetes, and evidence for many others is beginning to emerge. Therefore, it can be said that there is a dearth of novel therapeutics targeting the multiple aberrant immune responses in this condition.

Lipoxygenases are members of a family of enzymes involved in the synthesis of eicosanoids from arachidonic acid and related polyunsaturated fatty acids [17]. These eicosanoids, which are oxygenated derivatives of 20 -carbon fatty acids, include leukotrienes, lipoxins, hepoxilins, eoxins, resolvins, protectins and others [17]. Eicosanoids are important regulators of numerous systems in the human body, including growth after physical activity, inflammation or immunity, and messengers in the central nervous system. Lipoxygenases are implicated in various inflammatory diseases, including cancer, heart disease, asthma and diabetes [17]. Indeed, Nadler and colleagues, and others, have been investigating the role of leucocyte 12-lipoxygenase in diabetes since the mid-1990s [18, 19]. 12-Lipoxygenase peroxidates polyunsaturated fatty acids, including arachidonic acid and linoleic acid to generate lipid inflammatory mediators, such as 12-hydroperoxyeicosatetraenoic acid and 12 hydroxyeicosatetraenoic acid (12-HETE). However, the discovery of selective, potent inhibitors of 12-lipoxygenase has remained elusive. This prompted a large study that used quantitative high-throughput screening to identify selective inhibitors among a library of 153,607 compounds [20]. Several compounds were identified as exhibiting excellent specificity, $>50$-fold selectivity vs the paralogues 5-human lipoxygenase, reticulocyte 15-human lipoxygenase type-1 and epithelial 15-human lipoxygenase type 2 , and $>100$-fold selectivity vs ovine cyclooxygenase- 1 and human cyclooxygenase-2 [20].

With these tools in hand, Taylor-Fishwick and colleagues [21] set out to perform a proof-of-concept study investigating the efficacy of these small molecule inhibitors in rodent and human beta cells exposed to proinflammatory cytokines increased locally within islets in diabetes. Using two specific 12-lipoxygenase inhibitors, Compounds 5 and 9, the authors performed experiments designed to demonstrate the ability of these compounds to inhibit 12-HETE production in human islets and rodent beta cell lines in vitro. Compounds 5 and 9 were both effective in preventing the detrimental effects of IL$1 \beta$, TNF $\alpha$ and IFN $\gamma$ on glucose-stimulated insulin secretion in human islets and rodent beta cell lines. Compounds 5 and 9 also partially protected rodent beta cell lines, non-diabetic NOD mouse islets, and human islets from the pro-apoptotic effects of IL-1 $\beta$, TNF $\alpha$, and IFN $\gamma$, while in parallel, blunting islet mRNA expression of $M C P 1$ (also known as CCL2) and $I L-12 p 40$. Finally, Compound 5 also showed acute systemic efficacy in vivo, reducing plasma 12-HETE levels by over $60 \%$, with a calculated half life of $2.72 \mathrm{~h}$ following an oral bolus administration of $50 \mathrm{mg} / \mathrm{kg}$.

Indeed, an impressive body of preclinical studies supports the clinical development of 12-lipoxygenase inhibitors for the treatment of diabetes. This includes studies showing that mice with knockout of the 12-lipoxygenase gene (Alox12) were protected from multiple low-dose streptozotocin-induced diabetes and from diabetes development on the NOD background [19, 22]. Germline Alox 12 knockout mice were also protected from high-fat-diet-induced glucose intolerance [23] and insulin resistance [24]. Systemic deletion of 12-lipoxygenase appeared to have no effect on glucose homeostasis or islet development in the absence of diabetes-inducing stressors, suggesting therapeutic targeting of this molecule would have minimal adverse effects $[19,23,24]$. To address the tissuespecific actions of 12-lipoxygenase, both adipocyte and pancreatic-specific Alox12 knockout mice were developed $[25,26]$. Deletion of 12-lipoxygenase from either tissue protected from high-fat-diet-induced glucose intolerance [25, 26], while pancreatic 12-lipoxygenase deletion also protected from multiple low dose streptozotocin-induced diabetes [26]. The benefit of studying tissue-specific deletion of genes is that it allows for more targeted studies on the actions of a given molecule in a specific cell type (e.g. the pancreatic beta cell), while confirming its cell autonomous effects in vivo. At the molecular level, depletion of 12-lipoxygenase in islets was found to increase the ability of beta cells to handle oxidative stress, by upregulating the transcription factor nuclear factorlike 2 (NRF2) [26]. This resulted in increased islet antioxidant enzymes, superoxide dismutase 1 (SOD1) and glutathione peroxidase 1 (GPX1), in response to high-fat-diet feeding [26]. Together with previous studies on human islets [27], 
these data suggest that clinical application of recently identified 12-lipoxygenase inhibitors may help preserve islet cell function during impaired glucose tolerance or in established type 2 diabetes.

Unfortunately, a limitation of the study by Taylor-Fishwick and colleagues is the lack of in vivo translation of their newly discovered 12-lipoxygenase inhibitors for the treatment of rodent models of diabetes. The authors report that achieving parenteral formulations of their compounds to perform longterm proof-of-concept studies was limited because of a lack of aqueous solubility. We look forward to seeing this limitation overcome in future studies using a recently identified new chemical class of selective inhibitors [28].

In addition to the in vivo translation of these studies, some future studies on the upstream and downstream molecular mechanisms definitively linking diabetes to 12-lipoxygenase activation in beta cells and alpha cells are warranted (see Fig. 1). For example, is 12-lipoxygenase only activated in beta cells by proinflammatory cytokines, or do lipids, hyperglycaemia and amyloid deposits also stimulate eicosanoid production? What is the molecular mechanism linking these agents to 12-lipoxygenase activation? A recent report that inhibition of $\mathrm{Ca}^{2+}$-independent phospholipase $\mathrm{A} 2$ ameliorates islet infiltration and the incidence of diabetes in NOD mice provides an interesting upstream therapeutic target [29]. How do 12-lipoxygenase products cause oxidative or endoplasmic reticulum stress in beta cells? Indeed, the recent identification of a potential 12-HETE receptor ( $G$ proteincoupled receptor 31; GPR31) [30] suggests activation via this G protein-coupled receptor could prove critical for transducing the effects of 12-lipoxygenase-derived 12-HETE in beta cells. Does 12-lipoxygenase regulate the membrane redox state in beta cells and thereby impair mitochondrial activity, or activate a redox-dependent cell death pathway as reported in other cell types? [31]. It may also be interesting to consider non-beta cell cell types in the islet as contributors to local 12HETE production (e.g. blood platelets and macrophages). Finally, since eicosanoids are essential molecules required during the classic inflammatory response and in the central nervous system, the benefits of 12-lipoxygenase inhibition will need to be weighed against any adverse effects.

Interestingly, leucocyte 12-lipoxygenase expression may have initially been thought to be restricted to immune cells, but it clearly also plays a role in beta cell function and survival. Perhaps there are other molecular mechanisms in immune cells that are critical for islet endocrine cell function and vice versa. The emergence of the immunometabolism field should provide numerous answers to these questions in

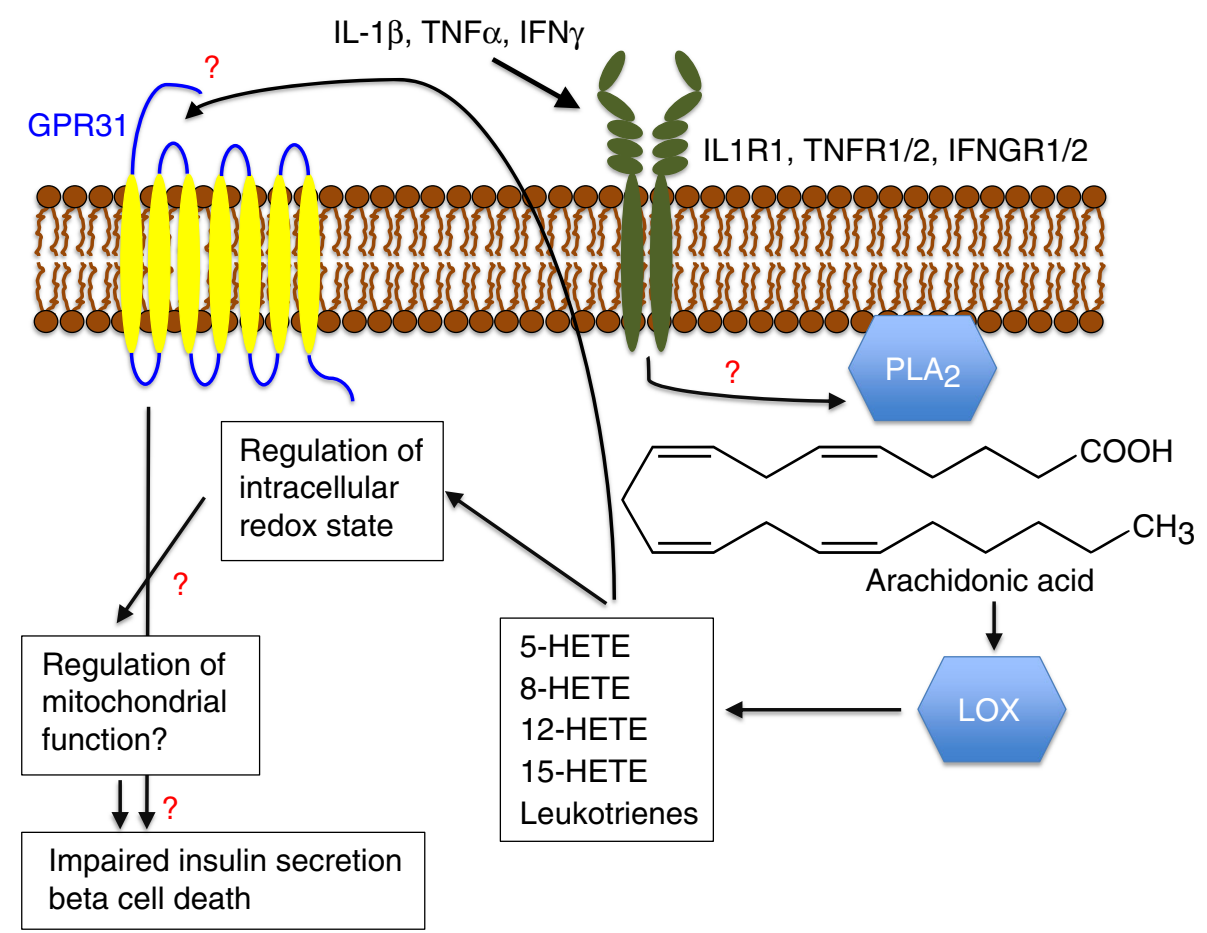

Fig. 1 Proposed mechanism by which 12-lipoxygenase transduces signals from proinflammatory cytokines in pancreatic beta cells. Proinflammatory cytokines (IL-1 $\beta$, and TNF $\alpha$ ) act on their cognate receptors (IL-1 receptor 1, IL1R1; TNF $\alpha$ receptor 1 or $2, \mathrm{TNFR} 1 / 2 ; \mathrm{IFN} \gamma$ receptor 1 and 2, IFNGR1/2), leading to intracellular phospholipase A2 activation $\left(\mathrm{PLA}_{2}\right)$ and the liberation of arachidonic acid. Arachidonic acid is oxygenated by various lipoxygenases (LOXs) to generate several hydroxyeicosatetraenoic acid (HETE) bioactive lipids or leukotrienes; 12-LOX specifically generates 12-HETE. Lipid permeable 12-HETE may act in an autocrine manner on its cognate receptor ( $\mathrm{G}$ proteincoupled receptor 31; GPR31) to regulate insulin secretion and/or beta cell death, or may influence the intracellular redox state of the beta cell, leading to mitochondrial dysfunction and/or redox-dependent cell death 
the years ahead, and hopefully provide insight into new therapies to treat diabetes.

Acknowledgements We thank all members of the Ehses and Donath laboratories for their insightful comments and feedback.

Funding Funding for work at the Ehses laboratory is provided by the Child \& Family Research Institute, the University of British Columbia, the Canadian Foundation for Innovation, the Canadian Diabetes Association, and the Canadian Institutes of Health Research. Funding for work in the Donath laboratory is provided by the University Hospital Basel, the Swiss National Foundation and the Juvenile Diabetes Research Foundation.

Duality of interest The authors have no duality of interest associated with this manuscript.

Contribution statement JAE and MYD were responsible for the conception and design of the manuscript, drafting the article, revising it critically for important intellectual content, and approval of the version to be published.

\section{References}

1. Kahn SE, Zraika S, Utzschneider KM, Hull RL (2009) The beta cell lesion in type 2 diabetes: there has to be a primary functional abnormality. Diabetologia 52:1003-1012

2. Tuomi T, Santoro N, Caprio S, Cai M, Weng J, Groop L (2014) The many faces of diabetes: a disease with increasing heterogeneity. Lancet 383:1084-1094

3. American Diabetes A (2014) Standards of medical care in diabetes2014. Diabetes Care 37(Suppl 1):S14-S80

4. Gepts W (1965) Pathologic anatomy of the pancreas in juvenile diabetes mellitus. Diabetes 14:619-633

5. In't Veld P (2011) Insulitis in human type 1 diabetes: the quest for an elusive lesion. Islets 3:131-138

6. Westwell-Roper C, Nackiewicz D, Dan M, Ehses JA (2014) Toll-like receptors and NLRP3 as central regulators of pancreatic islet inflammation in type 2 diabetes. Immunol Cell Biol 92:314-323

7. Chow SZ, Speck M, Yoganathan P et al (2014) Glycoprotein 130 receptor signaling mediates alpha-cell dysfunction in a rodent model of type 2 diabetes. Diabetes 63:2984-2995

8. Donath MY, Shoelson SE (2011) Type 2 diabetes as an inflammatory disease. Nat Rev Immunol 11:98-107

9. Nackiewicz D, Dan M, He W et al (2014) TLR2/6 and TLR4activated macrophages contribute to islet inflammation and impair beta cell insulin gene expression via IL-1 and IL-6. Diabetologia 57: 1645-1654

10. Eguchi K, Manabe I, Oishi-Tanaka Y et al (2012) Saturated fatty acid and TLR signaling link beta cell dysfunction and islet inflammation. Cell Metab 15:518-533

11. Westwell-Roper CY, Ehses JA, Verchere CB (2014) Resident macrophages mediate islet amyloid polypeptide-induced islet IL-1beta production and beta-cell dysfunction. Diabetes 63:1698-1711

12. Jourdan T, Godlewski G, Cinar R et al (2013) Activation of the Nlrp3 inflammasome in infiltrating macrophages by endocannabinoids mediates beta cell loss in type 2 diabetes. Nat Med 19:1132-1140
13. Gregor MF, Hotamisligil GS (2011) Inflammatory mechanisms in obesity. Annu Rev Immunol 29:415-445

14. Donath MY, Dalmas E, Sauter NS, Boni-Schnetzler M (2013) Inflammation in obesity and diabetes: islet dysfunction and therapeutic opportunity. Cell Metab 17:860-872

15. Lee HM, Kim JJ, Kim HJ, Shong M, Ku BJ, Jo EK (2013) Upregulated NLRP3 inflammasome activation in patients with type 2 diabetes. Diabetes 62:194-204

16. Donath MY (2014) Targeting inflammation in the treatment of type 2 diabetes: time to start. Nat Rev Drug Discov 13:465-476

17. Kuhn H, Banthiya S, van Leyen K (2014) Mammalian lipoxygenases and their biological relevance. Biochim Biophys Acta S13881981(14)00211-X

18. Bleich D, Chen S, Gu JL et al (1995) Interleukin-1 beta regulates the expression of a leukocyte type of 12-lipoxygenase in rat islets and RIN m5F cells. Endocrinology 136:5736-5744

19. Bleich D, Chen S, Zipser B, Sun D, Funk CD, Nadler JL (1999) Resistance to type 1 diabetes induction in 12-lipoxygenase knockout mice. J Clin Invest 103:1431-1436

20. Kenyon V, Rai G, Jadhav A et al (2011) Discovery of potent and selective inhibitors of human platelet-type 12-lipoxygenase. J Med Chem 54:5485-5497

21. Taylor-Fishwick DA, Weaver J, Glenn L et al (2014) Selective inhibition of 12-lipoxygenase protects islets and beta cells from inflammatory cytokine-mediated beta cell dysfunction. Diabetologia. doi:10.1007/s00125-014-3452-0

22. McDuffie M, Maybee NA, Keller SR et al (2008) Nonobese diabetic (NOD) mice congenic for a targeted deletion of 12/15-lipoxygenase are protected from autoimmune diabetes. Diabetes 57:199-208

23. Nunemaker CS, Chen M, Pei H et al (2008) 12-Lipoxygenaseknockout mice are resistant to inflammatory effects of obesity induced by Western diet. Am J Physiol Endocrinol Metab 295:E1065E1075

24. Sears DD, Miles PD, Chapman J et al (2009) 12/15-Lipoxygenase is required for the early onset of high fat diet-induced adipose tissue inflammation and insulin resistance in mice. PLoS One 4:e7250

25. Cole BK, Morris MA, Grzesik WJ, Leone KA, Nadler JL (2012) Adipose tissue-specific deletion of 12/15-lipoxygenase protects mice from the consequences of a high-fat diet. Mediat Inflamm 2012:851798

26. Tersey SA, Maier B, Nishiki Y, Maganti AV, Nadler JL, Mirmira RG (2014) 12-Lipoxygenase promotes obesity-induced oxidative stress in pancreatic islets. Mol Cell Biol 34:3735-3745

27. Ma K, Nunemaker CS, Wu R, Chakrabarti SK, Taylor-Fishwick DA, Nadler JL (2010) 12-Lipoxygenase products reduce insulin secretion and $\beta$-cell viability in human islets. J Clin Endocrinol Metab 95:887-893

28. Luci DK, Jameson JB 2nd, Yasgar A et al (2014) Synthesis and structure-activity relationship studies of 4-((2-hydroxy-3methoxybenzyl)amino)benzenesulfonamide derivatives as potent and selective inhibitors of 12-lipoxygenase. J Med Chem 57:495-506

29. Bone RN, Gai Y, Magrioti V et al (2014) Inhibition of $\mathrm{Ca}^{2+}$ independent phospholipase $\mathrm{A}_{2}\left(\mathrm{iPLA}_{2} \beta\right)$ ameliorates islet infiltration and incidence of diabetes in NOD mice. Diabetes. doi: $10.2337 / \mathrm{db} 14-0097$

30. Guo Y, Zhang W, Giroux C et al (2011) Identification of the orphan G protein-coupled receptor GPR31 as a receptor for 12-(S)hydroxyeicosatetraenoic acid. J Biol Chem 286:33832-33840

31. Seiler A, Schneider M, Forster H et al (2008) Glutathione peroxidase 4 senses and translates oxidative stress into 12/15-lipoxygenase dependent- and AIF-mediated cell death. Cell Metab 8:237-248 